WSRC-TR-2003-00284

Revision 0

\title{
Fiber-Optic Laser Raman Spectroscopy Sensor
}

\section{Kristine Eland Zeigler, Robert J. Lascola, and Laura L. Tovo} Westinghouse Savannah River Company Aiken, SC 29808

\author{
Unclassified \\ Does Not Contain Unclassified Controlled Nuclear Information (UCNI)
}

June 30, 2003 
Westinghouse Savannah River Company Savannah River Site

Aiken, SC 29808

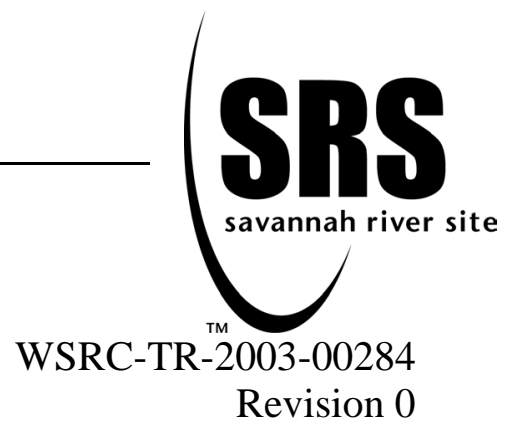

Keywords:

Raman, hydrogen isotopes, in-situ sensor

Classification: $\mathrm{U}$

\section{Fiber-Optic Laser Raman Spectroscopy Sensor}

Kristine Eland Zeigler, Robert J. Lascola, and Laura L. Tovo

Publication Date: June 30, 2003

Westinghouse Savannah River Company

Savannah River Site

Aiken, SC 29808 
This document was prepared in conjunction with work accomplished under Contract No. DE-AC09-96SR18500 with the U. S. Department of Energy.

\section{DISCLAIMER}

This report was prepared as an account of work sponsored by an agency of the United States Government. Neither the United States Government nor any agency thereof, nor any of their employees, makes any warranty, express or implied, or assumes any legal liability or responsibility for the accuracy, completeness, or usefulness of any information, apparatus, product or process disclosed, or represents that its use would not infringe privately owned rights. Reference herein to any specific commercial product, process or service by trade name, trademark, manufacturer, or otherwise does not necessarily constitute or imply its endorsement, recommendation, or favoring by the United States Government or any agency thereof. The views and opinions of authors expressed herein do not necessarily state or reflect those of the United States Government or any agency thereof.

This report has been reproduced directly from the best available copy.

Available for sale to the public, in paper, from: U.S. Department of Commerce, National Technical Information Service, 5285 Port Royal Road, Springfield, VA 22161, phone: (800) 553-6847, fax: (703) 605-6900

email: orders@ntis.fedworld.gov

online ordering: http://www.ntis.gov/help/index.asp

Available electronically at http://www.osti.gov/bridge

Available for a processing fee to U.S. Department of Energy and its contractors, in paper, from: U.S. Department of Energy, Office of Scientific and Technical Information, P.O. Box 62, Oak Ridge, TN 37831-0062,

phone: (865)576-8401,

fax: (865)576-5728

email: $\underline{\text { reports@ adonis.osti.gov }}$ 
WSRC-TR-2003-00284, Rev. 0 June 30, 2003

Page 4 of 25

\section{TABLE OF CONTENTS}

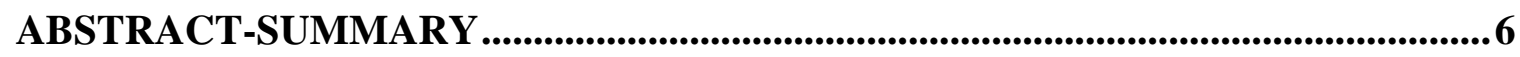

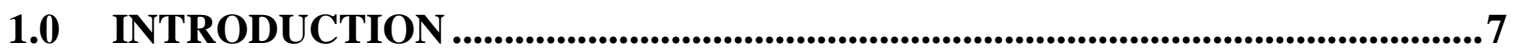

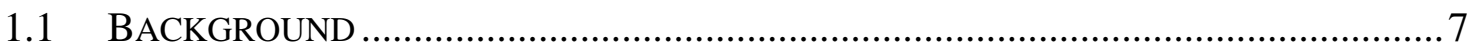

1.2 ADVANTAGES AND DISADVANTAGES OF RAMAN............................................

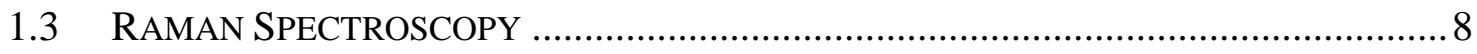

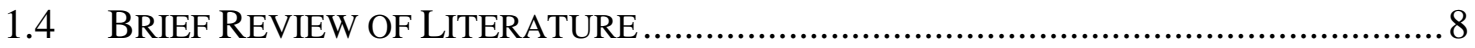

1.5 HYDROGEN-TRITIUM THERMAL CYCLE ABSORPTION PROCESS (HT TCAP)......9

2.0 EXPERIMENTAL...................................................................................................10

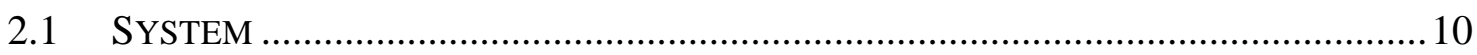

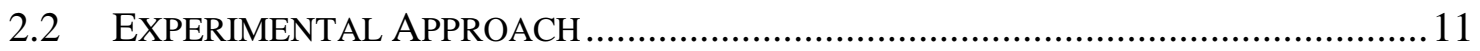

3.0 RESULTS AND DISCUSSION .........................................................................11

3.1 VERIFICATION OF THE RAMAN HD PEAK …………........................................ 11

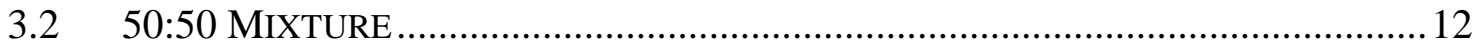

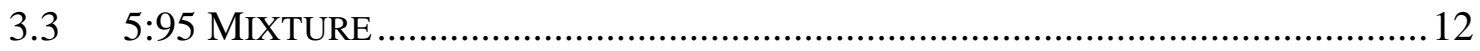

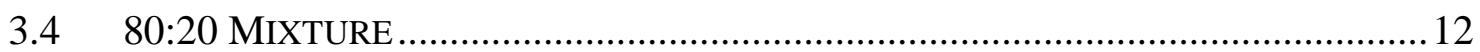

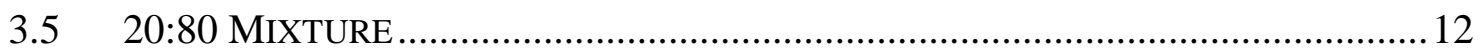

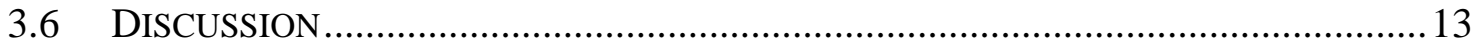

4.0 CONCLUSIONS..................................................................................................... 13

5.0 ACKNOWLEDGEMENTS ..........................................................................................13

6.0 REFERENCES ............................................................................................................. 14 


\section{LIST OF FIGURES}

Figure 1. Schematic of fiber-optic laser Raman set-up ....................... 15

Figure 2. Raman system components ..................................... 16

Figure 3. Spectra of $\mathrm{H}_{2}, \mathrm{D}_{2}$ and $\mathrm{HD}$ mixture using MS and Raman .............. 17

Figure 4. Raman spectrum of a 50:50 mixture of $D_{2}$ and $H_{2}$ at 2886 torr ........... 18

Figure 5. Raman spectrum of a 5:95 mixture of $\mathrm{D}_{2}$ and $\mathrm{H}_{2}$ at 1530 torr .......... 19

Figure 6. Raman spectrum of an 80:20 mixture of $\mathrm{D}_{2}$ and $\mathrm{H}_{2}$ at $2953 \mathrm{torr} . \ldots \ldots . .20$

Figure 7. Raman spectrum of a 20:80 mixture of $D_{2}$ and $H_{2}$ at 3229 torr ......... 21

\section{LIST OF TABLES}

Table 1. MS and Raman isotopic ratio comparisons for a mixture of $\mathbf{H}_{2}, \mathbf{D}_{2}$, and $\mathrm{HD}$ at a pressure of 1750 torr

Table 2. S: $N$ ratios for the extreme pressure readings of the $D_{2}: H_{2}$ mixtures 23

Table 3. Noise and $S: N$ ratio calculations for increasing accumulations........... 24

Table 4. $\mathrm{H}_{2}: \mathrm{D}_{2}$ ratios of the various mixtures

\section{LIST OF ACRONYMS and ABBREVIATIONS}

\begin{tabular}{|c|c|}
\hline ADS & Analytical Development Section \\
\hline CCD & charge-coupled device \\
\hline DOE & Department of Energy \\
\hline $\mathbf{D}_{2}$ & deuterium \\
\hline $\mathbf{H}_{2}$ & protium \\
\hline HD & protium-deuterium \\
\hline MS & mass spectrometry \\
\hline $\mathbf{m W}$ & milliWatts \\
\hline $\mathbf{n m}$ & nanometer \\
\hline PFR & plug flow reverser \\
\hline psi & pounds per square inch \\
\hline RGA & residual gas analyzer \\
\hline $\mathbf{S}: \mathbf{N}$ & signal to noise \\
\hline SRTC & Savannah River Technology Center \\
\hline SRS & Savannah River Site (Aiken, SC) \\
\hline $\mathbf{T}_{\mathbf{2}}$ & tritium \\
\hline HT TCAP & hydrogen-tritium thermal cycling absorption process \\
\hline
\end{tabular}


WSRC-TR-2003-00284, Rev. 0

June 30, 2003

Page 6 of 25

\begin{abstract}
SUMMARY
The Defense Programs Plant Directed Research and Development Program sponsored the optimization and interface of a fiber-optic Raman sensor as a complementary technique to mass spectrometry currently used in the Tritium Facility for measuring hydrogen isotopes. This sensor will provide real-time feedback while reducing the sample load for off-line gas analysis by the Tritium Facility mass spectrometers. The compact Raman system incorporates a 488 nanometer laser system, spectrometer and detector along with a 20foot fiber-optic probe. The analysis of gas mixtures of protium and deuterium at various compositions and total pressures ranging from 11 to 5000 torr showed good signal to noise ratios using very short integration times (15 seconds). The detection limits for protium and deuterium ranged from $0.5 \%-0.8 \%$. This probe will be demonstrated in-line in the new HT TCAP (hydrogen-tritium thermal cycling absorption process) cold runs.
\end{abstract}


WSRC-TR-2003-00284, Rev. 0

June 30, 2003

Page 7 of 25

\subsection{INTRODUCTION}

\subsection{Background}

On-line analysis is the most effective means for obtaining process feedback and control. Reactant and product concentrations are quickly determined and the process is not disturbed by sampling. Fiber-optic based spectroscopy is a method by which these criteria can be met. Raman spectroscopy has been successfully demonstrated for the measurement of hydrogen isotopes. By coupling Raman with fiber-optics, measurement of hydrogen isotopes can be performed in-situ, quickly, allowing the adjustment of the process controls to obtain the desired final product. We have proposed to interface and optimize a fiber-optic Raman sensor and demonstrate it in the hydrogen-tritium thermal cycling absorption process (HT TCAP).

Currently, mass spectrometry (MS) is the preferred method for measurement of hydrogen isotopes in the Tritium Facilities at the Savannah River Site (SRS) and other Department of Energy (DOE) complexes. Although this technique is very reliable, the high resolution laboratory MS systems currently in use in the Tritium Facilities are nearing their maximum working life. The vendor has stopped production of these instruments, and support will be minimal over the next ten years. In addition, high resolution $(>=2800)$ mass spectrometers are large and impractical for direct process measurements. Quadrupole mass spectrometers are smaller and have been used as in-line process monitors but are only useful in applications where unit resolution is sufficient.

\subsection{Advantages and Disadvantages of Raman}

A fiber-optic Raman sensor is a complementary technique to MS, with several distinct advantages. Raman can simultaneously measure all the hydrogen isotopes. Current high resolution MS systems can measure some of the hydrogen isotopes but cannot directly measure them all. Because Raman can be coupled with fiber-optics, samples can be measured in-situ, with no need to pull samples off-line. The sample remains in its environment, undisturbed and intact, with no need for pressure reduction or long lengths of capillary tubing. As with MS, very small sample volumes are needed and the resulting spectra are easy to interpret. The system needed for the Raman measurements is generally smaller and less expensive than most commercially available MS systems.

Raman does however have some disadvantages. Generally, the detection limits for Raman are slightly higher than MS. The signal is weak, as only $0.00001 \%$ of incident photons will be Raman scattered. While the signal can be improved with longer exposure times or higher laser powers, the advantages of quick measurements using small, simple and less expensive equipment will be quickly lost. Also, fluorescence from the sample or fiber-optics can obscure the Raman signal in some parts of the spectrum. This effect does not hinder this application as the vibrational shifts of hydrogen isotopes are well separated from the fluorescence regions. Another disadvantage is that any monatomic species, such as helium, cannot be measured by the Raman technique. Despite these disadvantages, Raman is a viable technique because it will meet the detection limit requirements for most processes and reduce the sample load on the older instruments, while analyzing for the hydrogen isotopes in-situ. 
WSRC-TR-2003-00284, Rev. 0

June 30, 2003

Page 8 of 25

\subsection{Raman Spectroscopy}

Spectroscopy based on the Raman effect has been long used for gas, solid and liquid analyses. The Raman effect itself arises when light is incident on a molecule. Most of the light is elastically scattered, that is the scattered light has the same energy, frequency and wavelength as the incident photons. Raman scattering occurs when some of the light's energy is transferred to vibrational or rotational modes of the molecule. The scattered light then occurs at a frequency that is shifted from the original by an amount corresponding to the energy lost to the molecule. This line position is given as a shift relative to the original wavelength. For a transition to be Raman active, there must be a change in the polarizability of the molecule associated with the excitation of the vibrational or rotational mode. The wavenumbers used in this study are of the transitions in the rotation-vibration branch, $\mathrm{Q}_{1}$ (region $2700 \mathrm{~cm}^{-1}$ to $4300 \mathrm{~cm}^{-1}$ ), of $\mathrm{H}_{2}$ (and its isotopes). These values are well known ${ }^{1-3}$ and mutually distinct, providing selectivity.

Another important feature of the Raman effect is that successful measurements generally require the use of lasers, as only one out of every ten million incident photons will be inelastically scattered. Lasers are the most effective means for providing a high photon flux. Additionally, as the effect occurs at characteristic wavelength shifts, a monochromatic (single wavelength) source will produce the most well defined scattering peaks. Lasers provide the closest approximation to this ideal.

\subsection{Brief Review of Literature}

Early work using Raman spectroscopy for the analysis of hydrogen isotopes demonstrated the ability to monitor reaction kinetics. The Material Science and Technology Division in the Tritium group at Los Alamos National Laboratory, along with a research group from the Japanese Atomic Energy Research Institute, designed a $4 \mathrm{~cm}^{3}$ flow through cell for near-real time observation of hydrogen mixes ${ }^{4,5}$. They were able to analyze the isotopes in less than two minutes, with detection limits of $0.02 \%$. They also determined the first order time constants for hydrogen isotopic exchange rates ${ }^{4,5}$. Uda and coworkers ${ }^{6}$ used Raman to analyze isotopic methanes in fusion fuel gas processing systems. In addition to a flow cell, they used fiber-optics to deliver the laser energy to the cell. They were able to achieve a detection limit of $0.5 \%$ for hydrogen and methane. Engelmann and coworkers ${ }^{7}$ used an ultra high vacuum tight stainless steel gas cell with very high quality silica windows to investigate the radiochemical reactions between methane and tritium. Mass spectrometry was combined with the laser Raman to create "a powerful combination of techniques for qualitative and quantitative analysis ${ }^{7}$." All of these efforts involve the use of an external gas cell, which is not compatible with the hydrogen separation process described below.

The study of fiber-optics and probes for in-situ Raman analysis has been carried out by many different research groups. Myrick and Angel $^{8}$ showed that it was possible to achieve good Raman signal using very long lengths of fibers. Chong and coworkers ${ }^{9}$ discussed the advantages of using the six collection fibers around one excitation fiber (6around-1) design. Dao and coworkers ${ }^{10}$ also explored many different types of solid and liquid analysis using various instrumentation designs along with different data treatment 
WSRC-TR-2003-00284, Rev. 0

June 30, 2003

Page 9 of 25

using the Raman laser fiber optic method (RLFO). Recently, Berg and coworkers ${ }^{11}$ discussed the performance of various fiber-optic Raman probes for gas analysis. They explored the use of filters, fiber types, fiber sizes and the number of fibers used. O'hira and coworkers ${ }^{12}$ also used fiber-optics to deliver the laser pulse and collect the signal from a cell. However, they used conventional optics rather than a monolithic probe design.

At SRS, remote chemical analysis using the Raman technique has been explored by Nave and coworkers ${ }^{13,14}$. This work used a rugged diffuse reflectance 6 -around-1 probe. The fibers were angled to achieve a better acceptance angle for reflected light. This probe was used in conjunction with a pressurized sample system. The 1-1/8 inch diameter bore stainless steel pressure cylinder had a motorized linear actuator to compress gas in a sample cell to pressures of 500 psi (pounds per square inch). A detection limit of $0.1 \%$ hydrogen was observed. Malstrom also performed a study that compared and crossvalidated Raman spectroscopy and real-time mass spectrometry for the analysis of hydrogen isotopes ${ }^{15}$.

\subsection{Hydrogen-Tritium Thermal Cycle Absorption Process (HT TCAP)}

The TCAP is used to separate hydrogen isotopes, semi-continuously. The primary function of the HT TCAP is to separate $\mathrm{H}_{2}$ from tritium of the Z-Bed Recovery gases. This composition is usually less than a percent of tritium in $\mathrm{H}_{2}$. The final outcome of the separation is the production of a stackable raffinate containing less than 5 ppm (parts per million) tritium and a high purity product, which should contain greater than $99 \%$ tritium with less than $0.1 \% \mathrm{H}_{2}$. The HT TCAP will also be used to duplicate the current 233-H TCAP deuterium-tritium separation. The feed gas for this process contains between $20 \%$ and $60 \%$ tritium in $\mathrm{D}_{2}$ and produces a raffinate purity of greater than $98 \% \mathrm{D}_{2}$ and a product purity of greater than $99 \%$ tritium.

The following is a very brief description of how the HT TCAP operates ${ }^{16}$. Separation of the isotopes is achieved by moving feed gas between a Pd/kieselguhr (catalyst) column and a plug flow reverser (PFR). The gas is moved by thermal cycling of the Pd/k column. Absorption of the gas from the PFR onto the cold column creates an isotopic concentration gradient in the column (-50 degrees Celsius). Desorption of the gas from the hot column back to the PFR only partially reverses the gradient (150 degrees Celsius). A steady state gradient is established after several cycles and a small fraction of the heavy and light isotopes are removed from each cycle.

The Raman probe will be demonstrated at the column midpoint. At this point, a predetermined amount of feed is placed in the middle of the column and after cycling, product and raffinate are withdrawn from opposite ends of the column. The midpoint determines what proportion of the gas is withdrawn from the product and raffinate for the next cycle. For HT TCAP cold run testing purposes, $\mathrm{H}_{2}$ and $\mathrm{D}_{2}$ will be separated. This separation will give critical process information for the eventual hot run tests using $\mathrm{H}_{2}$ and tritium.

There are HT TCAP column midpoint analysis requirements that the Raman system must meet in order to be successfully demonstrated. First, the entire HT TCAP occurs every 
WSRC-TR-2003-00284, Rev. 0

June 30, 2003

Page 10 of 25

40 minutes. The Raman system must be able to sample at the end of the hot cycle when the column is filling and as it begins to cool. The concentration of gases at this sampling point should be less than $5 \% \mathrm{D}_{2}$, greater than or equal to $95 \% \mathrm{H}_{2}$ and some HD. The pressure will range from $2500-3000$ torr ( \pm 500 torr) with a temperature of about 135 degrees Celsius.

\subsection{EXPERIMENTAL}

\subsection{System}

A schematic of the Raman system used is depicted in Figure 1. This system consists of a laser (a), spectrometer and charge coupled device (CCD) detector (b), probe (c, d) and computer for data acquisition. The laser system (Figure 1a), Sapphire 200-488 CW (Coherent Laser Group, Santa Clara, CA), emits at $488 \mathrm{~nm}$ with the power ranging from $25 \mathrm{~mW}$ to $200 \mathrm{~mW}$. This laser system consists of four parts: the laser head, heat sink for the laser head, control board and power supply. The laser is controlled via an RS-232 cable from the board by a terminal computer program. Because the laser arrived in these separate parts, ADS packaged it into a boxed system measuring 12 inches long, 13.5 inches wide, and 8.5 inches tall (Figure 2a). This system is now easily transportable and small enough to fit in tight spaces. A subminiature A (SMA) adapter was designed for the laser head so that the fiber-optic probe could be directly attached and the laser beam would be totally enclosed. This changes the laser status to a lower class, which allows safer operation in any environment. Another addition to the laser head was a 0.22 numerical aperture (NA) collimator, (World Precision Optics), to increase the amount of light entering the fiber. This collimator was placed on the laser head, before the fiberoptic, and allows for $85 \%$ of the light to reach the detection cell.

A 20-foot fiber-optic probe (RoMack, Inc., Williamsburg, VA) was acquired, consisting of 6 collection fibers around 1 excitation fiber (Figure 2b). These fibers have a 400 micron diameter and a 0.22 NA. The common end, or detection end, consists of a $1 / 2$ inch Swagelock VCR fitting for compatibility with the tee in the HT TCAP line (Figure 2c). The fiber breaks out 17 feet from the common end into two separate ends: one excitation fiber to the laser head (Figure 2a) and six collection fibers to the spectrometer (Figure $2 \mathrm{~d}$ ). Both of these ends are terminated with a SMA connector and the entire fiber is jacketed with flexible stainless steel with a Teflon inner tube. The probe was designed to be 20 feet to allow enough length in the glovebox for the probe to reach the detection tee and connect with the hardware outside of the glovebox.

Once the laser light is delivered to the tee and allowed to excite the gas molecules, the Raman signal is sent back down the fiber to the spectrometer (Figure 2d), which spectrally disperses the light. This spectrometer is a Holospec- f/1.8 I VIS from Kaiser Optical Systems, Inc. (Ann Arbor, MI). The Holospec contains a $488 \mathrm{~nm}$ grating along with a SuperNotch-Plus $488 \mathrm{~nm}$ filter to block the laser light from entering the CCD detector. This DV-420-OE CCD detector system (Andor Technology, South Windsor, CT) consists of a 1024 X 256 pixel array. The system comes with Hologram software to control the detector and acquire data. 
WSRC-TR-2003-00284, Rev. 0

June 30, 2003

Page 11 of 25

\subsection{Experimental Approach}

The intensity of the signal acquired is directly proportional to the laser power. For the current experiment, the laser is at its maximum power of $200 \mathrm{~mW}$. Initial experimental data was acquired using exposure times of 15 seconds and 5 seconds and averaging 5 accumulations (exposures). The exposure time is the amount of time the detector is exposed to the Raman signal, while the accumulation is number of spectra captured during this time. Both of these features can be changed by the user. Exposure times range from milliseconds to minutes. If greater than one accumulation is selected, the exposures are averaged, producing one spectrum. Better signal to noise ratios are obtained using longer exposure times and a greater number of accumulations. There is however a trade off; as the exposure time and accumulations are increased, the signal to background improves, but the time it takes to collect the results rapidly increases. For the work here, the total amount of time it takes for 1 spectrum to be collected using a 15 second exposure and 5 accumulations, is 150 seconds.

Canisters of $\mathrm{D}_{2}$ and $\mathrm{H}_{2}$ were obtained from Hydrogen Technology Section personnel at a 50:50 mix, 5:95 mix, 20:80 mix and an 80:20 mix. Total pressures of the mixtures were measured with a pressure transducer (Sensotec) placed on the detection tee. For each mixture, spectra were collected at various pressures, until the canister was emptied or a signal could no longer be discerned.

For signal to noise calculations, the noise was taken as 1/5 peak-to-peak of the baseline. Peak height was the signal and a background, taken as the average of the baseline on both sides of the peak, was subtracted from this. Standard deviations $(3 \sigma)$ were calculated for 5 averaged spectra for all compositions and exposures. Detection limits were calculated as 3 times the standard deviation of a blank measurement divided by the slope of a concentration plot.

The region of $2700 \mathrm{~cm}^{-1}$ to $4300 \mathrm{~cm}^{-1}$ is the area of the spectra being interrogated. In this region, we find the rotational-vibrational transitions of the hydrogen isotopes. $\mathrm{D}_{2}$ is found at a shift of $2971 \mathrm{~cm}^{-1}$, HD is found at $3632 \mathrm{~cm}^{-1}$, and $\mathrm{H}_{2}$ shifts at $4132 \mathrm{~cm}^{-13}$. For future investigations, $T_{2}$ can also be found in this region at a shift of $2466 \mathrm{~cm}^{-13}$.

\subsection{RESULTS AND DISCUSSION}

\subsection{Verification of the Raman HD peak}

To verify that the Raman signal at $3632 \mathrm{~cm}^{-1}$ was $\mathrm{HD}$, a mixture of $\mathrm{H}_{2}, \mathrm{D}_{2}$ and HD was simultaneously analyzed with the MS and Raman systems. (No HD standard was available at the time of analysis.) The MS system used was a Balzers QMG-421 consisting of a QMS-421 controller, QMH 400-5 RF generator, and QMA 400 quadrupole analyzer with an axial ion source and a 90 degree secondary electron multiplier. The system was pumped by a Balzers TPU 520 turbo pump backed by a Balzers TSD 020 pumping station. 
WSRC-TR-2003-00284, Rev. 0

June 30, 2003

Page 12 of 25

As seen in the MS spectrum (Figure 3a), $\mathrm{H}_{2}$ is at mass 2, $\mathrm{HD}$ is at mass 3 and $\mathrm{D}_{2}$ is at mass 4. The corresponding $\mathrm{H}_{2}, \mathrm{HD}$ and $\mathrm{D}_{2}$ peaks can be seen at their respective Raman shifts in the spectrum in Figure $3 \mathrm{~b}$. The $\mathrm{H}_{2}, \mathrm{HD}$ and $\mathrm{D}_{2}$ were the only species present in the mixture. The ratios of the isotopes measured by MS were determined by applying the appropriate instrument sensitivity factors to the measured ion currents. Table 1 shows a comparison of the MS isotope ratios to the measured Raman isotope ratios. The methods agree to within $15 \%$ of each other.

\subsection{0:50 Mixture}

Approximately 50 psi (2586 torr) of both $\mathrm{D}_{2}$ and $\mathrm{H}_{2}$ were placed in a canister for analysis. Figure 4 shows the spectrum of the 50:50 mixture with a total measured pressure of 2886 torr. The signal to noise $(\mathrm{S}: \mathrm{N})$ ratio for both the $\mathrm{H}_{2}$ and $\mathrm{D}_{2}$ are 500. Signal to noise ratios were still about 50 at the lowest pressure measured, 189 torr.

This canister was left on the shelf for several weeks before analysis and it is believed that $\mathrm{HD}$ began to form, as seen by the peak at $3632 \mathrm{~cm}^{-1}$ in Figure 4. At the time, this 50:50 composition was not verified by mass spectrometry. However, when the spectra from the 50:50 mixture and the $\mathrm{H}_{2}, \mathrm{D}_{2}$, and HD mixture (described in Section 4.1) were compared, the HD peaks overlapped at the same wavenumber, indicating that the peak is from HD.

\subsection{5:95 Mixture}

The total starting pressure for the 5:95 mixture was 30 psi (1530 torr). The $\mathrm{D}_{2}$ signal could still be seen at 394 torr, but was hard to differentiate from the noise at lower pressures. At 394 torr, the signal to noise ratio for $\mathrm{D}_{2}$ was about 10 while the $\mathrm{H}_{2}$ was 252. We are able to readily identify both the $\mathrm{D}_{2}$ and the $\mathrm{H}_{2}$ peaks at a pressure of 1530 torr as seen in Figure 5. The signal to noise ratio for $\mathrm{D}_{2}$ was calculated to be 25 while that of $\mathrm{H}_{2}$ was 748 .

\subsection{0:20 Mixture}

Figure 6 shows the mixture of $80 \% \mathrm{D}_{2}$ and $20 \% \mathrm{H}_{2}$. The $\mathrm{S}: \mathrm{N}$ ratio for $\mathrm{D}_{2}$ is calculated to be 1002 while that of $\mathrm{H}_{2}$ is 448 at a total pressure of 2953 torr. Total pressures ranging from 11 torr to 4334 torr were analyzed.

In a paper by $\mathrm{Nave}^{14}$, a calculation to relate the number of hydrogen molecules to the original pressure was given. He stated that because the Raman signal is proportional to the number of molecules, and neither the signal nor the noise are dependent on the pressure (if the number of molecules is kept fixed), one can infer the variation in Raman signal as a function of concentration with this calculation. Using the above mentioned formula, the limit of detection was calculated to be $0.6 \%$ for $\mathrm{D}_{2}$ and $0.4 \%$ for $\mathrm{H}_{2}$. The total number of moles in this mixture was calculated to be 0.028 , following the ideal gas law.

\subsection{0:80 Mixture}


WSRC-TR-2003-00284, Rev. 0

June 30, 2003

Page 13 of 25

The final mixture shown, Figure 7, is that of $20 \% \mathrm{D}_{2}$ and $80 \% \mathrm{H}_{2}$. The results are very similar to the 80:20 mixture with the $S: N$ ratio of $D_{2}$ being 405 while that of $\mathrm{H}_{2}$ is 1000 . The total pressure for this mixture was 3229 torr. Like the previous mixture, data was collected down to 11 torr. The limit of detection for $\mathrm{D}_{2}$ is $0.4 \%$ while that of $\mathrm{H}_{2}$ is $0.5 \%$.

\subsection{Discussion}

The figures in this report are a selected few of all the data acquired. These particular figures were chosen and discussed because they coincide with the pressure regions that will be analyzed in the HT TCAP. The detection limits for this Raman probe were good and within the HT TCAP process requirements. To further improve the detection limits, the exposure time or the accumulations can be increased. If the noise is decreased by two fold, then the limit of detection will lower by two fold. To monitor additional sampling points in the HT TCAP process or other Tritium Facility processes requiring lower detection limits, techniques such as surface enhanced Raman spectroscopy can be applied.

Signal to noise ratios were very good for the various mixtures at differing pressures. The data for the extreme pressures for each composition are given in Table 2. These ratios can however, be improved by increasing the exposure times or increasing the number of accumulations (exposures). Signal to noise values for four different sets of accumulations are compared and can be found in Table 3. As the number of accumulations increases, the noise decreases by about half each time, while the $S: N$ ratio slightly doubles.

Table 4 shows the approximate $\mathrm{H}_{2}: \mathrm{D}_{2}$ ratios for each mixture. A table of ratios similar to Table 4 will be used to estimate the column midpoint ratios during the HT TCAP demonstration of the fiber-optic Raman system. Additional isotopic compositions must be analyzed to improve the range covered.

\subsection{CONCLUSIONS}

A fiber-optic Raman system was optimized for use in the HT TCAP for the analysis of hydrogen isotopes. This system is able to analyze for $\mathrm{H}_{2}$ and $\mathrm{D}_{2}$ at the specified pressures of the column midpoint. Good signal to noise ratios are achieved with a 15 second exposure. Demonstration of this probe in the HT TCAP is scheduled for fiscal year 2003.

\subsection{ACKNOWLEDGEMENTS}

The authors thank Don Pak of ADS for the design and construction of the laser container and coupling parts. The information on the HT TCAP was provided by David Jacobs and Anita Poore of SRTC. William Rogier and Jackie Johnson of the Hydrogen Technology Section supplied the $\mathrm{H}_{2}$ and $\mathrm{D}_{2}$ mixtures. 
WSRC-TR-2003-00284, Rev. 0

June 30, 2003

Page 14 of 25

\subsection{REFERENCES}

(1) Veirs, K.; US DOE LBL-20565, UC-34A, 1985.

(2) Veirs, D. K. and Rosenblatt, G. M. J Mol. Spectrosc. 1987, 121, 401-419.

(3) Engelmann, U.; US DOE HNF-MR-0532, 1997.

(4) O’hira, S., Nakamura, H., Konishi, S., Hayashi, T., Okuno, K., Naruse, Y., Sherman, R. H., Taylor, D. J., King, M. A., Bartlit, J. R., and Anderson, J. L. Fusion Tech 1992, 21, 465-470.

(5) Sherman, R. H., Taylor, D. J., Bartlit, J. R., and Anderson, J. L., O'hira, S., Nakamura, H., Konishi, S., Okuno, K., and Naruse, Y. Fusion Tech 1992, 21, 457-461.

(6) Uda, T. O., K., and Naruse, Y. Fusion Tech 1992, 21, 436-441.

(7) Engelmann, U., Glugla, M., Penzhorn, R.-D., and Ache, H. J. Fusion Tech 1992, 21, 430-435.

(8) Myrick, M. L. and Angel, S. M. Appl. Spectrosc. 1990, 44, 565-570.

(9) Chong, C. K., Shen, C., Fong, Y., Zhu, J., Yan, F.-X., Brush, S., Mann, C. K., and Vickers, T. J. Vib. Spectrosc. 1992, 3, 35-45.

(10) Dao, N. Q. and Jouan, M. Sens. Act. B 1993, 11, 147-160.

(11) Berg, J. M., Rau, K. C., Veirs, D. K., Worl, L. A., McFarlan, J. T., Hill, D. D. Appl. Spectrosc. 2002, 56, 83-90.

(12) O’hira, S., Hayashi, T., Nakamura, H., Kobayashi, K., Yadokoro, T., Nakamura, N., Itoh, T., Yamanishi, T., Kawamura, Y., Iwai, Y., Arita, T., Maruyama, T., Kakuta, T., Konishi, S., Enoeda, M., Yamda, M., Suzuki, T., Nishi, M., Nagashima, T., and Ohta, M. Nucl Fus 2000, 40, 519.

(13) Nave, S. E., O’Rourke, P. E., Malstrom, R. A., and Prather, W. S. Proc. Control Qual. 1992, 3, 43-48.

(14) Nave, S. E.; US DOE WSRC-MS-96-0295, 1996.

(15) Malstrom, R. A.; US DOE SRT-ADS-97-0377, 1997.

(16) Moore, P. B., System Design Description for HT-Thermal Cycling Absorption Process System and Hot and Cold Nitrogen Systems (U), X-SYD-H-00013 rev 8, 2003. 
WSRC-TR-2003-00284, Rev. 0

June 30, 2003

Page 15 of 25

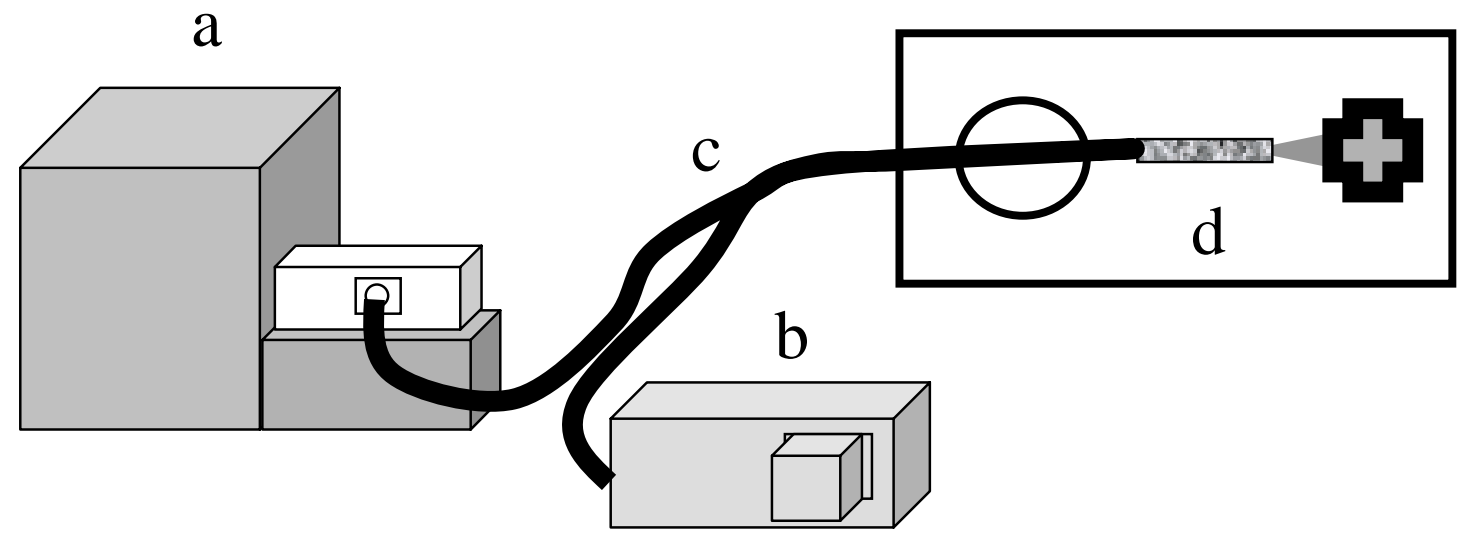

Figure 1. Schematic of fiber-optic laser Raman set-up; Includes (a) $488 \mathrm{~nm}$ laser system measuring 12" x 13.5" x 8.5"; (b) spectrograph and CCD detector (c) $20 \mathrm{ft}$. fiber-optic probe; and (d) fiber-optic probe head inside glovebox. 
WSRC-TR-2003-00284, Rev. 0

June 30, 2003

Page 16 of 25

a

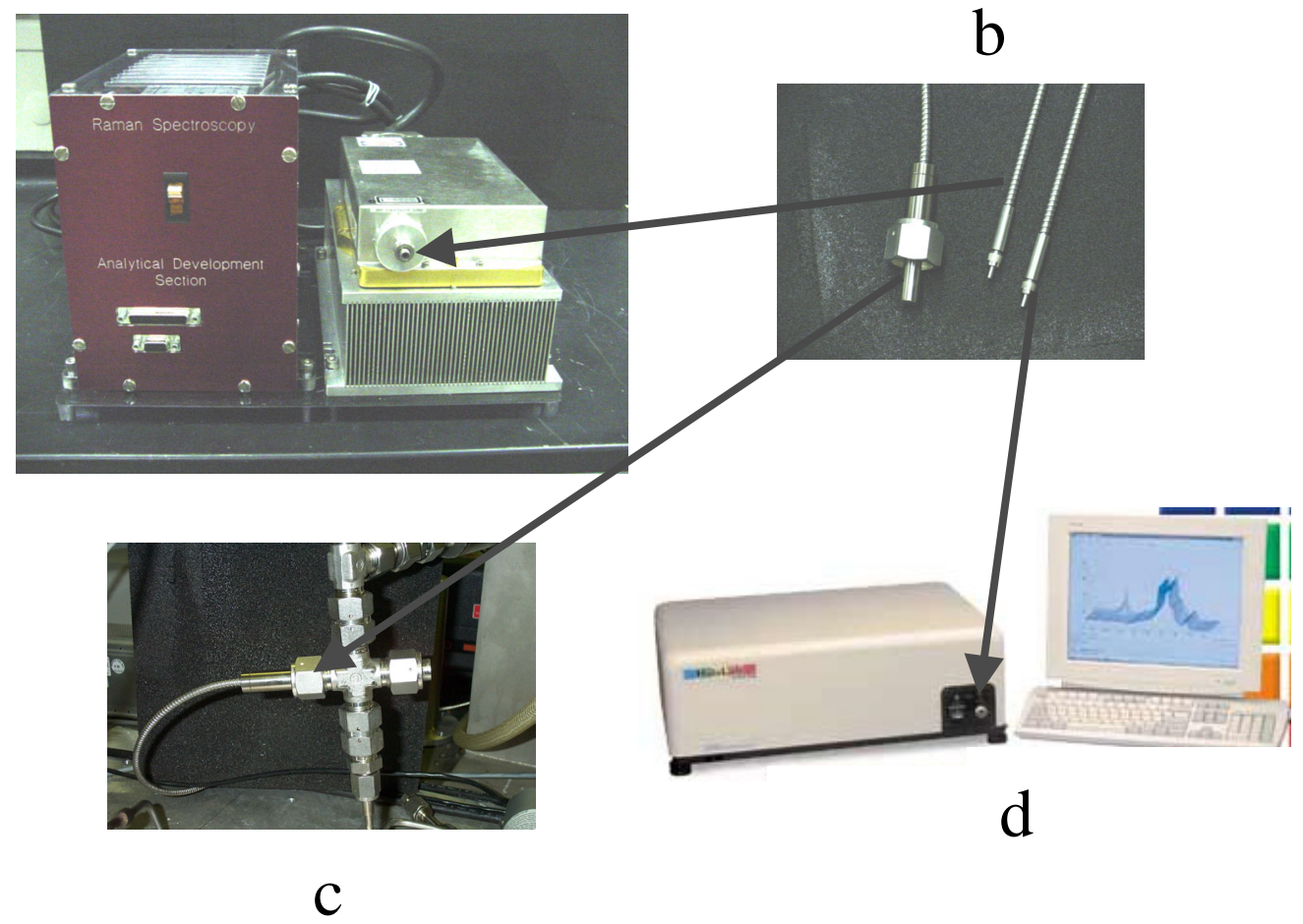

Figure 2. Raman system components;

(a) Packaged laser system. Break away excitation fiber is connected to the laser head. (b) Fiber-optic probe ends: common end (6 collection fibers around 1 excitation fiber) to plug into tee. Single ends (break away section of probe) to laser head (1 fiber) and to spectrometer (6 fibers). (c) Detection tee (inside glovebox) where common end is connected. (d) Spectrometer where break away collection fibers are connected. 
WSRC-TR-2003-00284, Rev. 0

June 30, 2003

Page 17 of 25

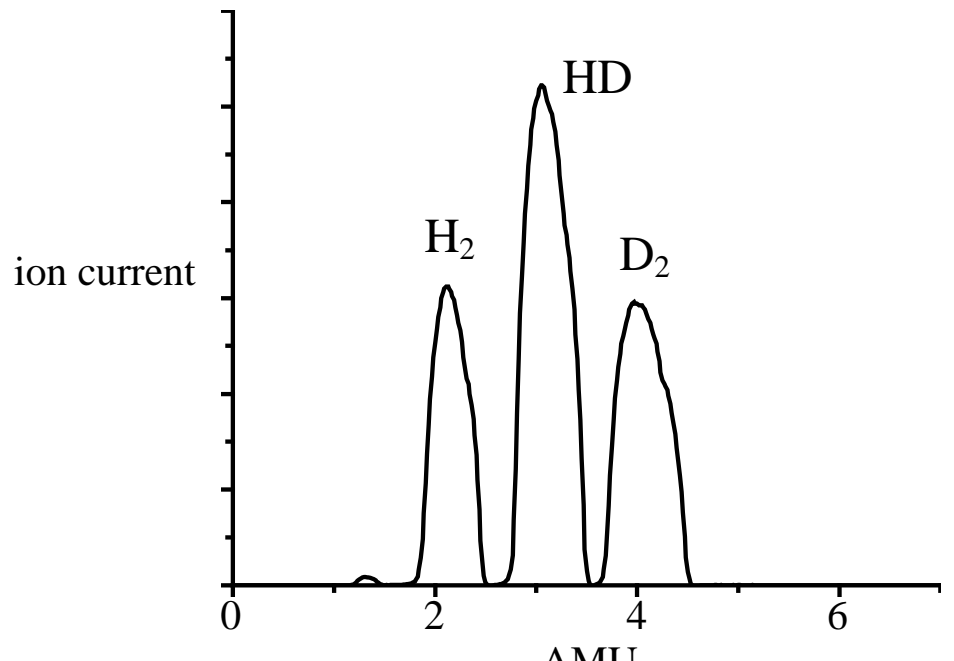

MS

(a)

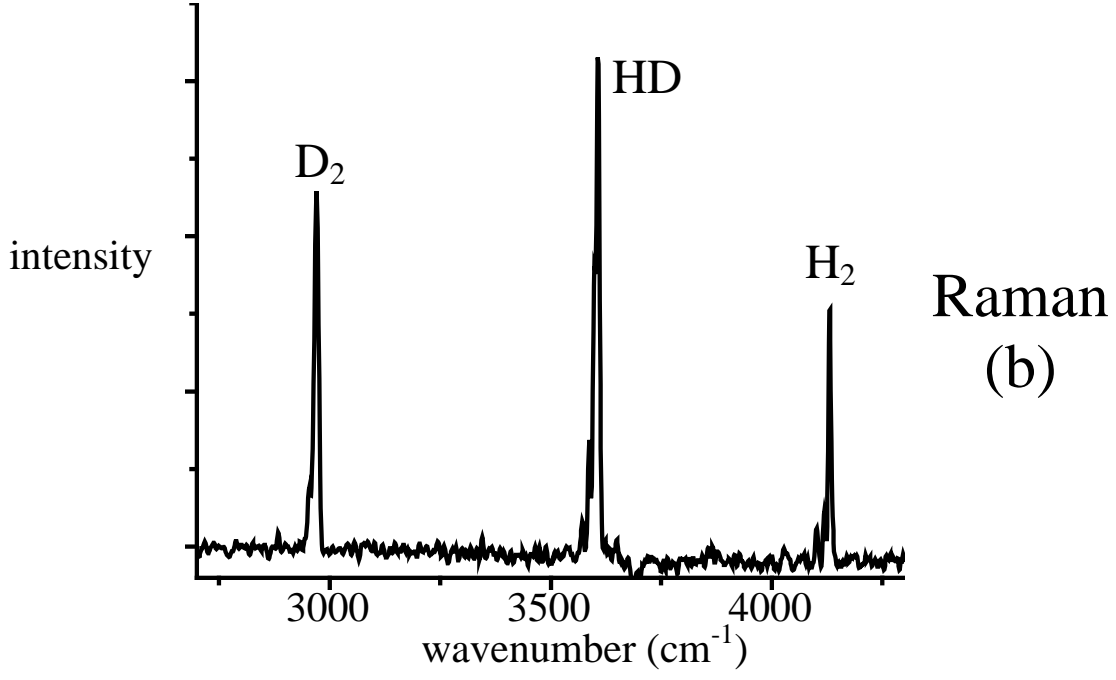

Figure 3. Spectra of $\mathrm{H}_{2}, \mathrm{D}_{2}$ and $\mathrm{HD}$ mixture using MS and Raman;

Verification of the HD Raman signal $\left(3632 \mathrm{~cm}^{-1}\right)$ by comparison to MS. For MS, the $\mathrm{H}_{2}$ has an atomic mass unit (AMU) of 2, $\mathrm{HD}$ is $3 \mathrm{AMU}$ and $\mathrm{D}_{2}$ is 4 AMU. 
WSRC-TR-2003-00284, Rev. 0

June 30, 2003

Page 18 of 25

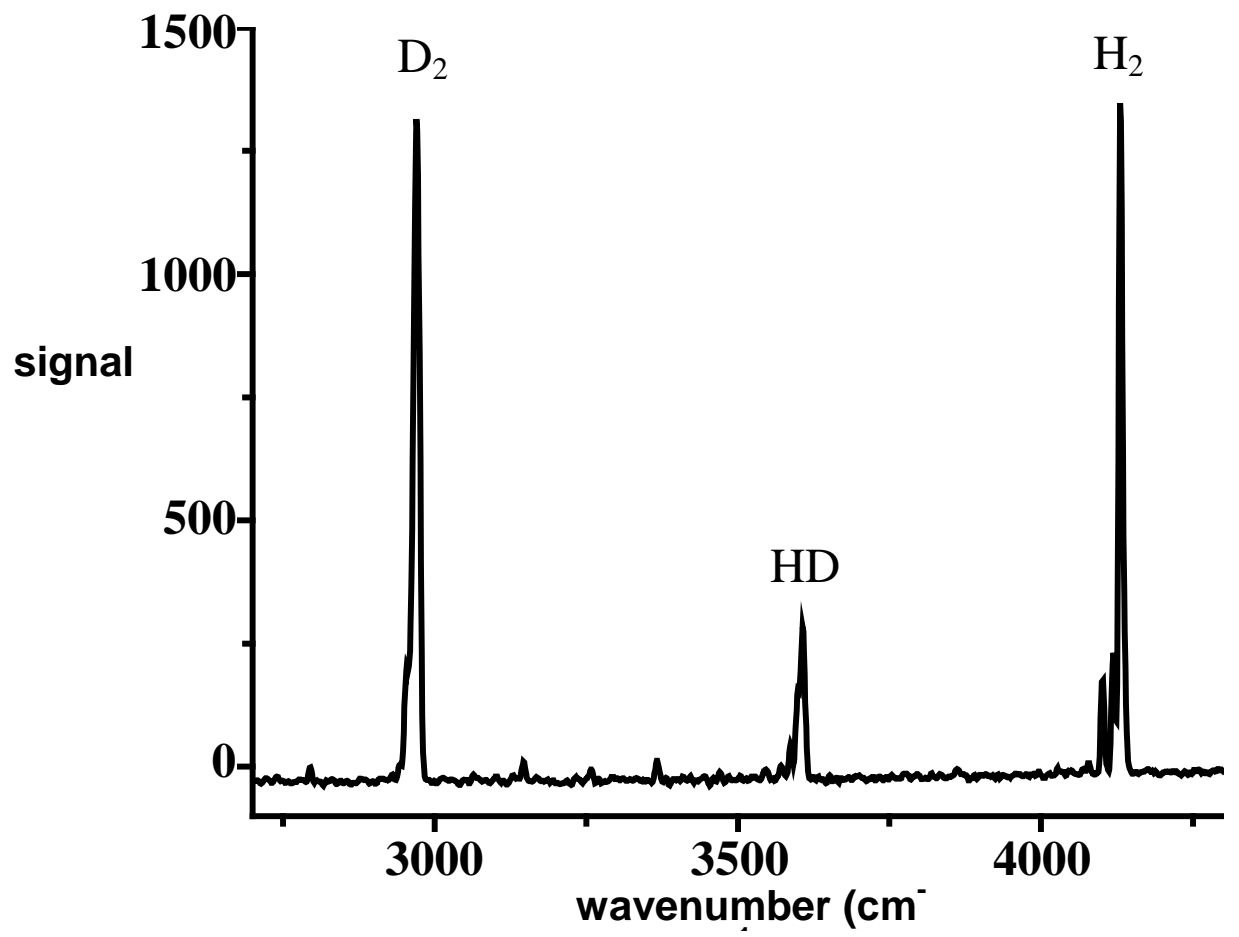

\begin{tabular}{|c|c|}
\hline & S: $\mathbf{N}$ \\
\hline $\mathbf{D}_{2}$ & $\mathbf{5 0}$ \\
\hline $\mathbf{H}_{2}$ & 53 \\
\hline
\end{tabular}

Figure 4. Raman spectrum of a 50:50 mixture of $\mathrm{D}_{2}$ and $\mathrm{H}_{2}$ at 2886 torr;

The $\mathrm{D}_{2}$ peak can be seen at a shift of $2994 \mathrm{~cm}^{-1}$ and the $\mathrm{H}_{2}$ peak is seen at $4155 \mathrm{~cm}^{-1}$. The peak at $3632 \mathrm{~cm}^{-1}$ is believed to be HD. Signal to noise ratios, both around 500 for $\mathrm{H}_{2}$ and $\mathrm{D}_{2}$ are calculated by taking the peak height (average background at both sides of the peak subtracted from the signal) divided by 1/5 peak-to-peak of the baseline. 
WSRC-TR-2003-00284, Rev. 0

June 30, 2003

Page 19 of 25

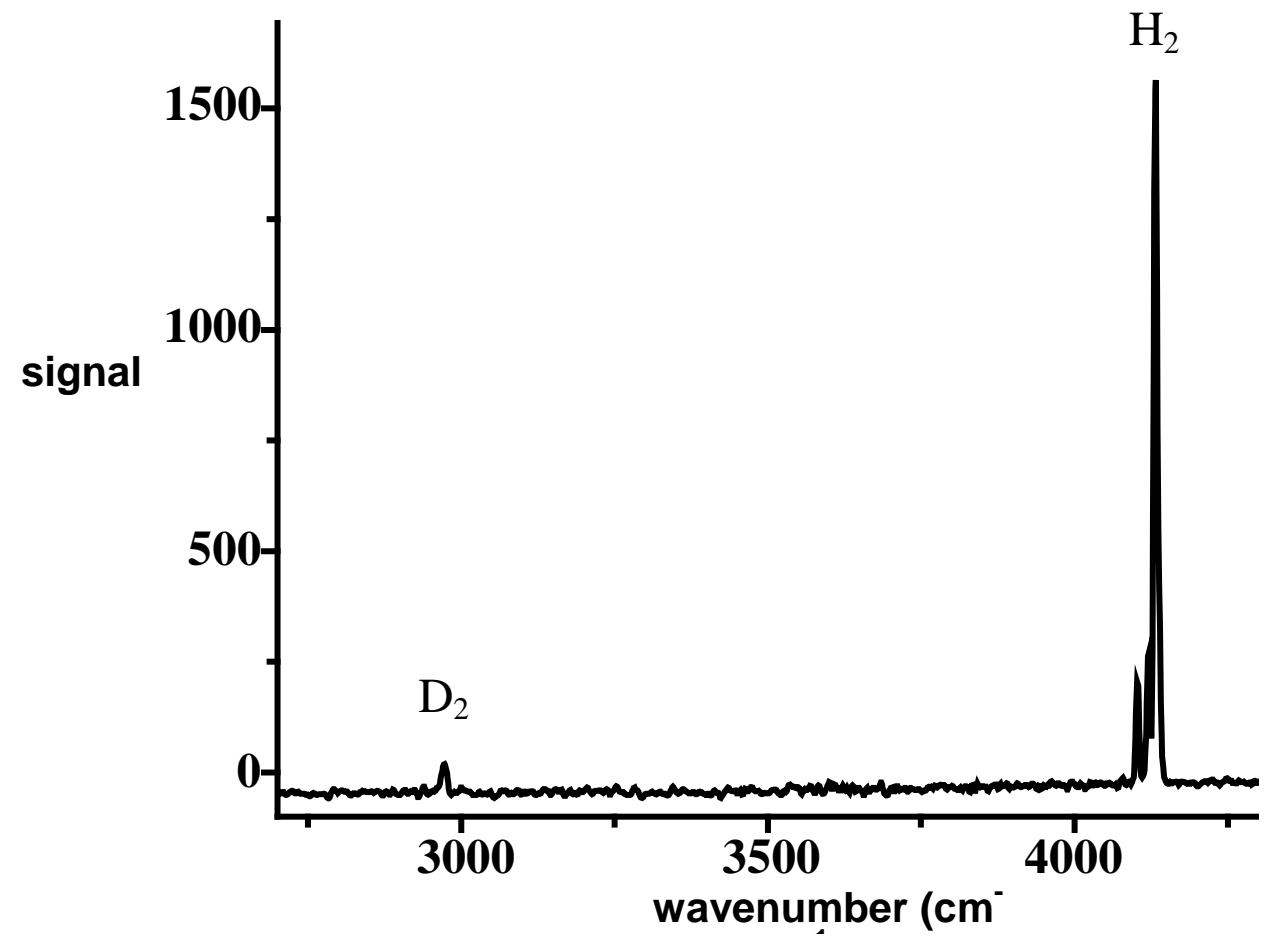

\begin{tabular}{|c|c|}
\hline & S:N \\
\hline$D_{2}$ & 25 \\
\hline$H_{2}$ & 748 \\
\hline
\end{tabular}

Figure 5. Raman spectrum of a 5:95 mixture of $\mathrm{D}_{2}$ and $\mathrm{H}_{2}$ at 1530 torr;

The $\mathrm{D}_{2}$ peak has a $\mathrm{S}: \mathrm{N}$ ratio of 25 , while that of $\mathrm{H}_{2}$ is greater than 700 . The $\mathrm{D}_{2}$ signal becomes lost in the noise around 394 torr. 
WSRC-TR-2003-00284, Rev. 0

June 30, 2003

Page 20 of 25

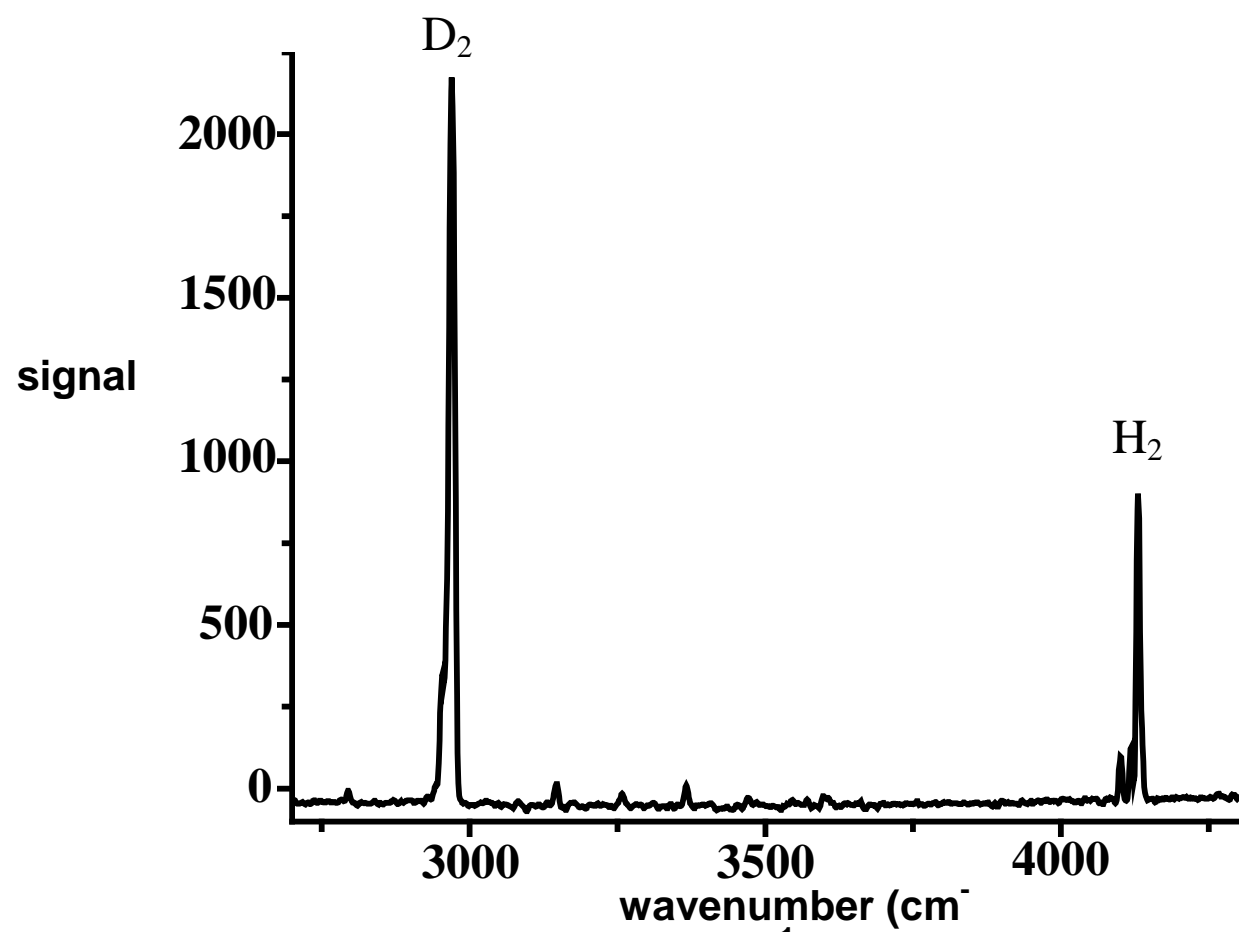

\begin{tabular}{|c|c|}
\hline & $S: N$ \\
\hline$D_{2}$ & 100 \\
\hline$H_{2}$ & 448 \\
\hline
\end{tabular}

Figure 6. Raman spectrum of an 80:20 mixture of $\mathrm{D}_{2}$ and $\mathrm{H}_{2}$ at 2953 torr;

The $D_{2}$ peak has a very good $S: N$ ratio of 1000 , while the $H_{2} S: N$ ratio is 448 . 
WSRC-TR-2003-00284, Rev. 0

June 30, 2003

Page 21 of 25

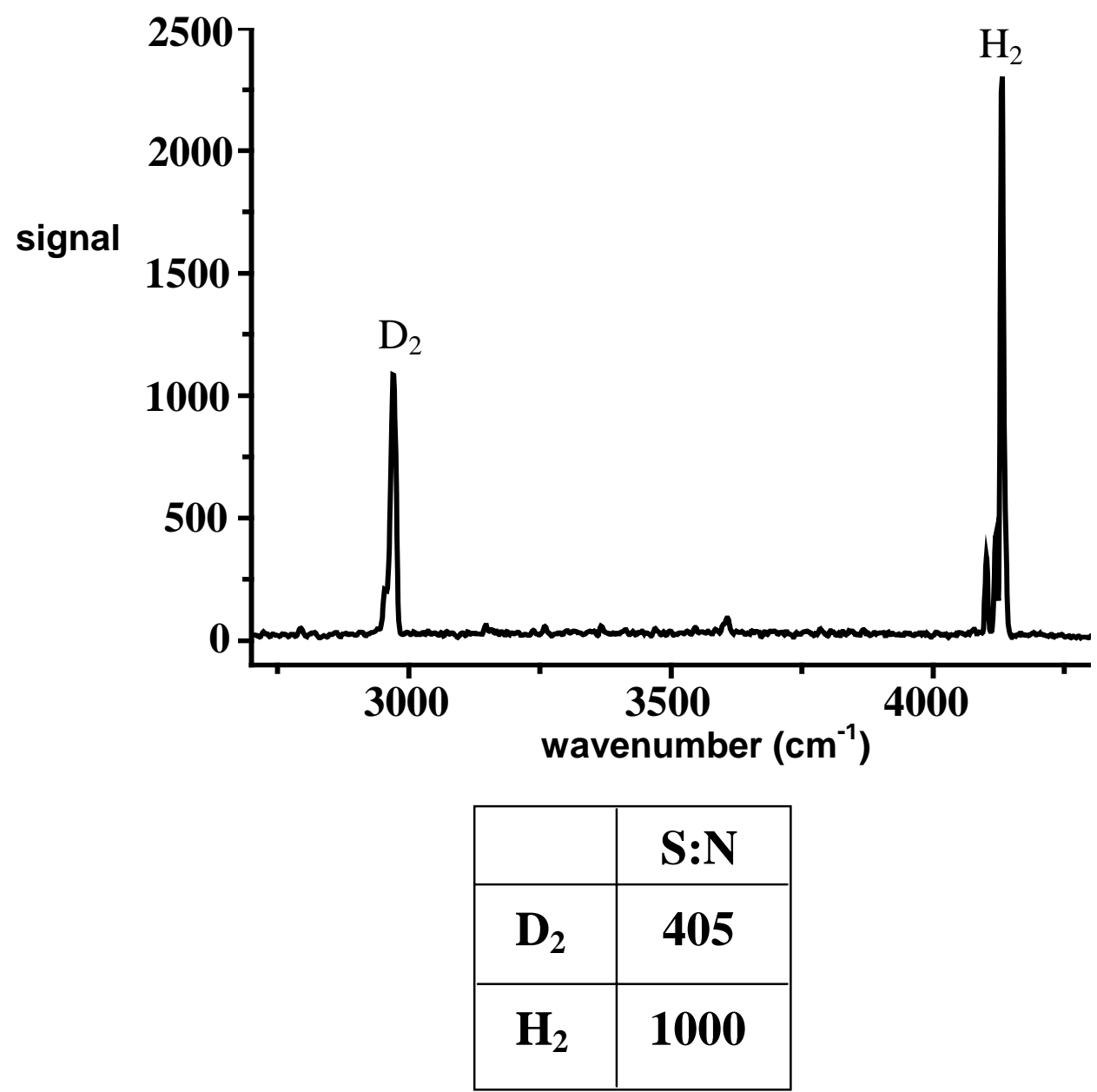

Figure 7. Raman spectrum of a 20:80 mixture of $\mathrm{D}_{2}$ and $\mathrm{H}_{2}$ at 3229 torr;

This mixture has comparable $\mathrm{S}: \mathrm{N}$ ratio values to the $80: 20 \mathrm{D}_{2}$ and $\mathrm{H}_{2}$ mixture (Figure 6). 
WSRC-TR-2003-00284, Rev. 0

June 30, 2003

Page 22 of 25

\begin{tabular}{|c|c|c|c|}
\hline & $\mathbf{H}_{2}: \mathbf{D}$ & $\mathbf{D}_{2}: \mathbf{H D}$ & $\mathbf{H}_{2}: \mathbf{H D}$ \\
\hline $\mathbf{M S}$ & 0.6 & 0.6 & 0.4 \\
\hline Raman & 0.7 & 0.7 & 0.5 \\
\hline
\end{tabular}

Table 1. MS and Raman isotopic ratio comparisons for a mixture of $\mathrm{H}_{2}, \mathrm{D}_{2}$, and $\mathrm{HD}$ at a pressure of 1750 torr. 
$50: 50$

\begin{tabular}{|c|c|}
\hline 3632 torr & $\mathrm{S}: \mathrm{N}$ \\
\hline $\mathrm{D}_{2}$ & 542 \\
\hline $\mathrm{H}_{2}$ & 513 \\
\hline
\end{tabular}

\begin{tabular}{|c|c|}
\hline 26 torr & $\mathrm{S}: \mathrm{N}$ \\
\hline $\mathrm{D}_{2}$ & 52 \\
\hline $\mathrm{H}_{2}$ & 59 \\
\hline
\end{tabular}

5:95

\begin{tabular}{|c|c|}
\hline 1530 torr & S:N \\
\hline$D_{2}$ & 25 \\
\hline$H_{2}$ & 748 \\
\hline
\end{tabular}

\begin{tabular}{|c|c|}
\hline 104 torr & S:N \\
\hline $\mathrm{D}_{2}$ & 11 \\
\hline $\mathrm{H}_{2}$ & 252 \\
\hline
\end{tabular}

$80: 20$

\begin{tabular}{|c|c|}
\hline 4334 torr & S:N \\
\hline $\mathrm{D}_{2}$ & 2155 \\
\hline $\mathrm{H}_{2}$ & 592 \\
\hline
\end{tabular}

\begin{tabular}{|c|c|}
\hline 11 torr & $\mathrm{S}: \mathrm{N}$ \\
\hline $\mathrm{D}_{2}$ & 42 \\
\hline $\mathrm{H}_{2}$ & 19 \\
\hline
\end{tabular}

$20: 80$

\begin{tabular}{|c|c|}
\hline 5062 torr & S:N \\
\hline $\mathrm{D}_{2}$ & 634 \\
\hline $\mathrm{H}_{2}$ & 1485 \\
\hline
\end{tabular}

\begin{tabular}{|c|c|}
\hline 11 torr & $\mathrm{S}: \mathrm{N}$ \\
\hline $\mathrm{D}_{2}$ & 9 \\
\hline $\mathrm{H}_{2}$ & 8 \\
\hline
\end{tabular}

Table 2. S:N ratios for the extreme pressure readings of the $\mathrm{D}_{2}: \mathrm{H}_{2}$ mixtures. 
WSRC-TR-2003-00284, Rev. 0

June 30, 2003

Page 24 of 25

\begin{tabular}{|c|c|c|}
\hline Accumulations & Noise & S:N \\
\hline 1 & 2.1 & 80 \\
\hline 5 & 1.1 & 15 \\
\hline 25 & 0.4 & 35 \\
\hline 10 & 0.2 & 70 \\
\hline
\end{tabular}

Table 3. Noise and $\mathrm{S}: \mathrm{N}$ ratio calculations for increasing accumulations; Calculated noise (1/5 peak-to-peak of the baseline) and $\mathrm{S}: \mathrm{N}$ ratios for increasing number of accumulations (exposures) for the $\mathrm{D}_{2}$ peak at 1804 torr. As the accumulations increase, the noise decreases by about half. 
WSRC-TR-2003-00284, Rev. 0 June 30, 2003

Page 25 of 25

\begin{tabular}{|c|c|}
\hline Mixture $\left(\mathrm{D}_{2}: \mathrm{H}_{2}\right)$ & $\sim \mathrm{H}_{2}: \mathrm{D}_{2}$ Ratio \\
\hline $5: 95$ & 26 \\
\hline $20: 80$ & 2 \\
\hline $50: 50$ & 1 \\
\hline $80: 20$ & 0.4 \\
\hline
\end{tabular}

Table 4. $\mathrm{H}_{2}: \mathrm{D}_{2}$ ratios of the various mixtures. 